\section{CAPACITAÇ̃̃O PARA O DESENVOLVIMENTO DE COMPETÊNCIAS PROFISSIONAIS NO PROCESSO DE ANÁLISE SOCIOECONÔMICA DOS ESTUDANTES DE GRADUAÇÃO}

\author{
PROFESSIONAL TRAINING FOR THE \\ DEVELOPMENT OF SKILLS TO THE PROCESS \\ OF SOCIOECONOMIC ANALYSIS OF \\ UNDERGRADUATE STUDENTS
}

Lilian Wrzesinski Simon lilian.uffs@gmail.com Doutoranda em Administração pela Universidade Federal de Santa Catarina. Florianópolis $S C-B R$.

\footnotetext{
Marcel Eduard Armanini marcel.armanini@uffs.edu.br Especialista em Gestão Pública na Educação Profissional e Tecnológica. Florianópolis - SC - $B R$.

Jucelio Kulmann de Medeiros juceliomedeiros@ifsc.edu.br Doutorando em Ciência e Tecnologia de Alimentos pela Universidade Federal do Rio Grande do Sul. Professor do Instituto Federal de Santa Catarina. Florianópolis - SC - BR.
}

\section{RESUMO}

O objetivo deste artigo é propor estratégias de capacitação das equipes técnicas responsáveis pelo processo de Análise Socioeconômica (AS) dos estudantes de graduação. A pesquisa é de natureza aplicada, caracterizada como descritiva e de abordagem qualitativa. Trata-se de uma pesquisa bibliográfica e documental, baseada em fontes de dados secundários. A análise realizada na Universidade Federal da Fronteira Sul (UFFS) apontou a necessidade de revisão do processo de AS e da elaboração de trilhas de capacitação para os profissionais de serviço social e administrativo, especialmente no que se refere à análise de renda e à avaliação de bens patrimoniais. As carências de profissionais observadas dificultam o afastamento desses profissionais por longos períodos. Portanto, essas ações de capacitação precisam ser ofertadas como programas de capacitação em serviço. A unificação da metodologia de análise de renda da matrícula e da AS também poderá reduzir etapas no processo de avaliação cadastral, conferindo maior agilidade e evitando retrabalhos.

Palavras-chave: Gestão de Processos. Gestão por Competências. Trilhas de Capacitação. Assistência Estudantil. Análise Socioeconômica.

\begin{abstract}
The objective of this study is to propose training strategies for the technical teams responsible for the Socioeconomic Analysis (SA) process of undergraduate students. The research is of an applied nature, characterized as descriptive and qualitative approach. It is a bibliographic and documental research, based on secondary data sources. The analysis carried out at the Federal University of Fronteira Sul (UFFS) showed that the need to review the SA process and the elaboration of training process for social servi-
\end{abstract}


ce and administrative professionals, especially regarding income analysis and evaluation of patrimony. The lack of professionals observed makes it difficult to keep these professionals away for long periods. For these reasons, these training actions must be offered as in-service training programs. The unification of the income analysis methodology of the enrollment and the SA may also reduce steps in the registration checking process, allowing more agility and avoiding rework

Keywords: Process Management. Competency Management. Continuous Training. Student Assistance. Socioeconomic Analysis.

\section{INTRODUÇÃO}

O desenvolvimento de pessoas por competências tem como principal finalidade promover o alinhamento das competências necessárias ao bom funcionamento da instituição com as competências individuais e organizacionais existentes, identificando as possíveis lacunas de competências que precisam ser desenvolvidas por meio da capacitação profissional. Pela capacitação, o indivíduo é direcionado a desenvolver novas competências, estimulando o valor social e, como consequência, o valor organizacional. A identificação das lacunas de competências no ambiente funcional indica possibilidades de construção de trilhas de desenvolvimento de pessoas ou trilhas de aprendizagem, a fim de auxiliar o processo de desenvolvimento de pessoas, bem como, no crescimento das instituições públicas (FLEURY; FLEURY, 2001, 2004; PIRES et al., 2005; MOREIRA; MUNCK, 2010; BERGUE, 2019).

Ao promover o desenvolvimento de pessoas por competências, as instituições públicas têm a oportunidade de desenvolver em estratégias que permitirão conectar as competências individuais às competências institucionais e às necessidades de padronização e uniformização dos processos (AVONA; BIGI; BIGI, 2014). Isso requer o conhecimento das principais competências organizacionais necessárias ao desenvolvimento da instituição e ao desempenho eficiente de seus processos burocráticos (BERGUE, 2019). Aos servidores públicos, essa dinâmica relaciona-se com o desempenhar de suas atividades junto ao compromisso de entregar serviços com qualidade e eficiência.

Nas universidades públicas federais, a gestão ainda necessita avançar no desenvolvimento e na otimização das competências individuais dos servidores, alinhando-as com as competências organizacionais. A universidade é uma organização complexa, permeada por uma série de processos burocráticos que podem ser mapeados, padronizados e agrupados para sua melhor execução (CARVALHO; SOUSA, 2017). Apesar de sua rigidez estrutural, o ambiente universitário apresenta um conceito dinâmico de troca de conhecimento e aprendizagem propícios para a melhoria dos processos organizacionais (PAIVA et al., 2017). A padronização dos processos, associada ao desenvolvimento de competências, reflete no alcance dos objetivos estratégicos da organização (REIS; BLATTMANN, 2004).

No âmbito da gestão acadêmica, o processo de Análise Socioeconômica (AS) é pré-requisito para os estudantes que pretendem realizar sua inscrição nos editais de concessão de auxílios financeiros e demais programas de Assistência Estudantil (AE) voltados aos alunos em condição de vulnerabilidade social, que ingressam nos cursos de graduação das universidades.

Este artigo tem como objetivo propor estratégias de capacitação das equipes técnicas responsáveis pelo processo de Análise Socioeconômica dos estudantes de graduação. Essas ações de capacitação visam à melhoria contínua dos fluxos de atendimento aos estudantes e à otimização dos processos burocráticos que permeiam esta área de atuação, os quais influenciam na eficiência das políticas e ações de AE, bem como no desempenho das equipes técnicas envolvidas.

O lócus escolhido para a análise foi a Universidade Federal da Fronteira Sul (UFFS). A UFFS foi implantada e consolidou-se em meio ao contexto de expansão e democratiza- 
ção do acesso ao ensino superior público, preconizada pelo Programa de Apoio a Planos de Reestruturação e Expansão das Universidades Federais (REUNI). O público-alvo prioritário da UFFS são estudantes egressos de escolas públicas, oriundos das esferas sociais menos favorecidas do campo e da cidade que, por longo período, almejavam ter acesso a uma universidade pública, gratuita e popular, voltada para as necessidades de desenvolvimento de sua região de abrangência (UFFS, 2020).

Desde a criação da UFFS, os processos e fluxos de trabalho da AE foram sendo desenvolvidos com o objetivo de assegurar o atendimento das necessidades socioeconômicas e de integração dos estudantes que passaram a ingressar na instituição. A instância que desenvolve os trabalhos da AE na UFFS é o Setor de Assuntos Estudantis (SAE). Esse setor, presente em todos os campi da UFFS, é coordenado e assessorado pela Pró-reitoria de Assuntos Estudantis (PROAE).

As equipes do SAE atuam no desenvolvimento de ações que estimulem a integração acadêmica e social dos estudantes, visando a auxiliar em sua permanência e sucesso acadêmico. Tal setor "também atua em atividades de acolhimento, integração e orientação ao universitário, buscando a prevenção da evasão e a formação integral, com apoio psicológico nos processos de ensino e aprendizagem, adaptação à universidade" (UFFS, 2020c, online). São os profissionais do SAE que realizam a avaliação do cadastro socioeconômico dos estudantes e desempenham todas as demais etapas do processo de AS.

Este estudo busca, na gestão de processos e na gestão por competências, possibilidades de avançar na proposição de trilhas de capacitação, que auxiliem os profissionais envolvidos no processo de AS no desenvolvimento de suas atividades. Espera-se que as contribuições aqui apresentadas possam qualificar ainda mais o trabalho desenvolvido pelas equipes técnicas e $o$ atendimento às demandas dos estudantes que procuram a $\mathrm{AE}$ como uma forma de permanecer na universidade.

\section{REVISÃO DE LITERATURA}

\subsection{GESTÃO DE PROCESSOS}

A Gestão de Processos abrange, em seu escopo, o conceito de processo de trabalho. Segundo Gonçalves (2000), o processo de trabalho está ligado a algo a ser desempenhado e que seja de cunho rotineiro, que influencie a organização na qual está inserida, podendo ser executado de diversas formas e com variados efeitos no que se refere ao impacto que pode agregar. Esse desempenho está associado às atribuições que os variados departamentos executam, padronizando procedimentos exigidos pelas tarefas, permitindo, ao mesmo tempo, um ajustamento, uma lógica e uma regularidade nas atividades desempenhadas, algo que se reverbera em um aumento da eficiência e eficácia do que é executado, elevando a aptidão do funcionário em abarcar mais responsabilidades (OLIVEIRA, 2005).

Por essa lógica, ao associar o trabalho com um setor e esse setor a uma pessoa, podemos levantar, também, aspectos a respeito da estrutura organizacional de uma instituição. Segundo Falcão Júnior e Santos (2016, p. 8):

A estrutura formal de uma organização estabelecida no organograma representa os aspectos básicos aos níveis da definição das tarefas. Entretanto, saber quais as funções que cada pessoa desempenha no interior da estrutura não tem muito sentido sem compreender como essas funções se relacionam umas com as outras. Portanto, para possibilitar uma real avaliação do desempenho das organizações, muitos teóricos organizacionais compreenderam que é preciso saber como as partes estão ligadas, atingindo seus processos.

Acerca do conceito de processo, diversas são as contribuições que examinam o tema. Falcão Júnior e Santos (2016) utilizam-se da concepção de Davenport (1994), que define o 
processo como um conjunto de práticas definidas e aferidas que objetivam a entrega de um produto específico para um cliente/fim específico, de forma contínua e ordenada, em que as tarefas necessárias se estruturam de forma ordenada temporal e fisicamente. Davenport (1994) também destaca que um processo se estrutura em um início (input) e um fim (output), além de focar no modo como o trabalho é efetuado em uma organização, ou seja, no processo de produção, em contraponto de pensar tão apenas no produto em si. Ainda, segundo Reis e Blattmann (2004, p. 6), "todos os processos necessitam da retroalimentação (feedback) que viabiliza mudanças significativas na condução dos processos".

Sob a perspectiva de um órgão público, o extinto Ministério do Planejamento, Orçamento e Gestão (BRASIL, 2011) abordou o conceito de processo como um mecanismo que possibilita associar quem desempenha o trabalho às diretrizes estratégicas dos órgãos públicos, propiciando que estes almejem seus objetivos. Ainda, tal ministério ressaltou que a perspectiva de atendimento das demandas dos cidadãos é o principal enfoque dos processos do setor público, devendo estes ter os respectivos processos modelados, gerenciados e automatizados, algo que permite um maior controle e qualidade nos serviços prestados.

Seguindo esta lógica, é possível adentrar em outros conceitos que ajudam a moldar a chamada Gestão de Processos, entre os quais, está o que se denomina de modelagem ou mapeamento de processo. O mapeamento é uma das principais etapas da gestão por processos, no qual se começa com o objetivo principal de um processo e, na sequência, se fraciona tal objetivo em tarefas e atividades. $\mathrm{O}$ mapeamento demonstra de que maneira são feitas as variadas atividades, do início ao fim, contribuindo, também, para que se possa melhorar sua execução, identificando pontos críticos, oportunidades de melhorias e, em alguns casos, pontos incongruentes ou ilógicos (HARRINGTON, 1993; FALCÃO JÚNIOR; SANTOS, 2016). Além disso, é preciso considerar que os pro- cessos podem ser agrupados em macroprocessos, os quais, por sua vez, são subdivididos em subprocessos ou grupos de atividades, sendo que o critério de agrupamento apropriado decorre da forma como se pretende fazer essa análise (REIS; BLATTMANN, 2004).

A efetividade na prestação dos serviços aos cidadãos exige dos gestores públicos um conhecimento pleno a respeito dos processos que culminarão neste serviço, tanto que o Decreto $\mathrm{n}^{0}$ 9.094, de 17 de julho de 2017, em seu Art. $1^{\circ}$, já vislumbra princípios sistêmicos e de gestão de processos entre os quais a atuação integrada e sistêmica na expedição de documentos, racionalização de métodos e procedimentos de controle, eliminação de formalidades e exigências cujo custo econômico ou social seja superior ao risco envolvido, aplicação de soluções tecnológicas que visem a simplificar processos e procedimentos de atendimento aos usuários dos serviços públicos, entre outros (BRASIL, 2017).

Dessa forma, a Gestão de Processos mostra-se como uma metodologia sólida tanto nas organizações privadas, quanto nas públicas $\mathrm{e}$, neste contexto, também aplicável às universidades (PAIVA et al., 2017). Tal método, cujo objetivo principal é melhorar os resultados de desempenho por meio do aperfeiçoamento dos processos de trabalho, também envolve os servidores ao passo que estes executam suas práticas de forma ininterrupta e os instigam a entender, analisar, modificar e monitorar a práxis de seu trabalho (BRASIL, 2013). Para Reis e Blattmann (2004, p. 6), "os processos não criam apenas as eficiências do presente, mas também garantem o futuro por meio de habilidades, isto é, a forma de fazer é que se aplica aos novos produtos e serviços".

Todavia, Carvalho e Sousa (2017) apontam que a reformulação nos processos já existentes no âmbito das universidades púbicas encontra resistências associadas a fatores, como o medo da mudança e os interesses pessoais e corporativos, os quais, por vezes, obstruem iniciativas de sua implantação. Nesse sentido, é de fundamental importância a conscientização de 
todos os partícipes a respeito das tarefas que desenvolvem, com o que desenvolvem, com quem desenvolvem e para quem é o resultado final do trabalho desenvolvido (PAIVA et al., 2017). Os autores Reis e Blattmann (2004) defendem que é necessário trabalhar, de forma interligada, a Gestão de Processos com a Gestão por Competências, uma vez que o desenvolvimento de habilidades também deve ser considerado para otimizar os processos da organização.

\subsection{GESTÃO POR COMPETÊNCIAS}

Acerca da Gestão por Competências, cabe destacar, inicialmente, que a concepção de competência não possui uma vertente única e consensual na literatura. Para chegar a uma definição conceitual do termo, Fleury e Fleury (2001, 2004) partiram da designação do termo preconizada pelo senso comum, "utilizada para designar uma pessoa qualificada para realizar alguma coisa" (FLEURY; FLEURY, 2001, p. 184), adentraram na perspectiva norte-americana, que caracteriza competência como um "conjunto de conhecimentos, habilidades e atitudes" inerentes à inteligência e à personalidade das pessoas que justificam um alto desempenho e abraçaram as contribuições da literatura europeia, que extrapola a perspectiva do indivíduo e da tarefa, visando a atingir situações complexas por meio da combinação de capacidades que podem ser desenvolvidas pelos indivíduos e pelas organizações (FLEURY; FLEURY, 2001, 2004).

Para os autores, competência é "um saber agir responsável e reconhecido, que implica mobilizar, integrar, transferir conhecimentos, recursos e habilidades, que agreguem valor econômico à organização e valor social ao indivíduo" (FLEURY; FLEURY, 2001, p. 188). No caso das instituições públicas, essa dimensão vai além da perspectiva de valor para a organização e para os profissionais que nela atuam, pois, também, é importante considerar o valor gerado para a sociedade, uma vez que o atendimento ao interesse público é uma das principais prerrogativas da Administração Pública (AP). A preocupação com os usuários se traduz na combinação dos recursos públicos disponíveis para a sua transformação em produtos e serviços com qualidade e eficiência (PIRES et al., 2005; BERGUE, 2019).

Em complemento, Paiva e Lopes (2008) ressaltam a importância do desenvolvimento de competências profissionais, as quais conceituam como a mobilização, pelo profissional, de um conjunto de saberes de naturezas diferenciadas, que possam gerar resultados reconhecidos individual, coletiva, econômica e socialmente. Os autores reforçam que, nessa concepção, estão reunidas competências compostas por saberes variados, que contribuem para dar cumprimento ao papel dos profissionais e das organizações na sociedade.

A combinação de conhecimentos e de experiências pessoais e profissionais é indispensável para o desenvolvimento de competências (FLEURY; FLEURY, 2001). Nesse sentido, Moreira e Munck (2010) chamam a atenção para o fato de que não basta apenas ao indivíduo possuir determinados conhecimentos e técnicas, mas que é necessário saber empregá-los. "O profissional competente sabe o que fazer com o conhecimento que tem e o usa habilmente" (MOREIRA; MUNCK, 2010, p. 80). Os autores também destacam que, quando o profissional não possui o conhecimento necessário para a ação ou para o cumprimento das tarefas, ele o busca junto aos seus pares ou na sua rede de contatos.

Conforme Fleury e Fleury (2001), esse caminho perpassa pela aprendizagem individual, pela aprendizagem em grupo e pela aprendizagem na organização. Os autores destacam que "a aprendizagem é um processo neural complexo, que leva à construção de memórias" (FLEURY; FLEURY, 2001 p. 190) e pode ser obtida por meio de diversas formas de aprendizado, que podem ser: lendo, ouvindo, errando, praticando, mentalizando, refletindo, observando os outros, etc. Esse processo é particular de cada pessoa e pode ser influenciado pelas emoções e pela afetividade. Esses sentimentos geram estímulos que impactam na motivação do indivíduo para aprender (FLEURY; FLEURY, 2001). 
Em nível organizacional, o desenvolvimento de competências está relacionado à definição da estratégia de negócio, à identificação das competências essenciais e das competências existentes e ao alinhamento das competências existentes com a estratégia da organização (FLEURY; FLEURY, 2001, 2004; MOREIRA; MUNCK, 2010). Esse processo evidenciará as possíveis lacunas de competências que precisam ser desenvolvidas por meio de trilhas de aprendizagem ou trilhas de capacitação.

O grande desafio da transformação de conhecimentos em competências está em "como passar da aprendizagem individual para a organizacional" (FLEURY; FLEURY, 2001, p. 92). "Ao desenvolverem competências essenciais para o sucesso da organização", as pessoas também "estão investindo em si mesmas" (FLEURY; FLEURY, 2001, p. 94), mas o objetivo principal nesse processo é que elas aprendam e possam aplicar o conhecimento adquirido na organização, que tenham oportunidades de fazê-lo e sejam motivadas para tal. Portanto, o estabelecimento de planos de desenvolvimento de pessoas que permitam aos indivíduos ampliar suas potencialidades, aplicá-las no desempenho de suas atribuições e serem reconhecidos por esse esforço, por meio da melhoria dos indicadores de resultados, entre outros incentivos, é fundamental para o sucesso da organização (AVONA; BIGI; BIGI, 2014).

Nas instituições públicas, os desafios são ainda maiores, pois os esforços na implantação da Gestão por Competências são mais recentes, e os processos de gestão de pessoas são menos flexíveis (PIRES et al., 2005; BERGUE, 2019). A Gestão por Competências na AP ganhou impulso com a publicação do Decreto $\mathrm{n}^{\circ}$ 5.707, de 23 de fevereiro de 2006, que instituiu a Política Nacional de Desenvolvimento de Pessoal (PNDP) (BRASIL, 2006). Essa política foi atualizada pelo Decreto $n^{\circ}$ 9.991, de 07 de novembro de 2019 e tem como objetivo "promover o desenvolvimento dos servidores públicos nas competências necessárias à consecução da excelência na atuação dos órgãos e das entidades da Administração Pública fede- ral direta, autárquica e fundacional" (BRASIL, 2019). Consequentemente, nas universidades federais, a gestão de pessoas também precisa continuar evoluindo no sentido de direcionar os servidores a desenvolver e a otimizar suas competências individuais, alinhando-as com as competências organizacionais.

\section{PROCEDIMENTOS METODOLÓGICOS}

O percurso metodológico adotado neste artigo perpassa pela realização de uma pesquisa de natureza aplicada, caracterizada, quanto aos objetivos, como descritiva e baseada em abordagem qualitativa. O contexto de estudo é o processo de AS dos estudantes de graduação que procuram os programas de AE da UFFS. Em relação às fontes de informações utilizadas, trata-se de pesquisa bibliográfica e documental, realizada por meio da coleta e análise de dados secundários (TRIVIÑOS, 1987; MARCONI; LAKATOS, 2002).

Os procedimentos adotados para a coleta de dados foram uma pesquisa bibliográfica sobre os temas Gestão por Processos e Gestão por Competências, associados a uma pesquisa documental em fontes de informações públicas disponibilizadas pela UFFS (TRIVIÑOS, 1987; MARCONI; LAKATOS, 2002). Entre os documentos que embasaram a análise estão resoluções internas da universidade que versam sobre a AE e a AS, relatórios de atividades da PROAE e resultados das ações adotadas para atender às recomendações da Auditoria Interna (AUDIN) em relação aos apontamentos e fragilidades encontradas no processo de AS.

A análise dos dados coletados é descritiva e puramente qualitativa (TRIVIÑOS, 1987; MARCONI; LAKATOS, 2002). A técnica empregada é a análise documental (TRIVIÑOS, 1987; MARCONI; LAKATOS, 2002). Ao caracterizar a pesquisa como estudo de caso, pode-se dizer que o caso a ser investigado não é a instituição em si, mas o processo de AS dos estudantes de graduação da UFFS (YIN, 2001; PRODANOV; FREITAS, 2013). É sobre esse 
processo que se debruçam os esforços da análise e a proposição de melhorias (YIN, 2001; PRODANOV; FREITAS, 2013). Os profissionais do SAE são os agentes que desempenham as atividades relacionadas ao processo em questão. Portanto, sobre eles recai a responsabilidade pela efetividade do processo e para eles que são dedicadas às trilhas de capacitação que poderão melhorar os indicadores de resultados e o dimensionamento das tarefas que precisam ser desempenhadas para assegurar esses resultados.

Contudo, apesar de a análise realizada na UFFS apresentar particularidades exclusivas da instituição em questão, o processo de AS é realizado no âmbito de toda a rede federal de ensino, sob diferentes denominações, de modo que os resultados também podem trazer contribuições aplicáveis em outros contextos.

\section{ANÁLISE DO PROCESSO DE ANÁLISE SOCIECONÔMICADOS ESTUDANTES DE GRADUAÇÃO DA UFFS}

A UFFS, lócus de pesquisa deste artigo, possui em seu organograma um Escritório de Processos (EP), criado em 2016, responsável por "realizar estudos sobre estruturas e procedimentos administrativos, propondo medidas para o seu contínuo aperfeiçoamento e maior eficiência na execução das atividades da Universidade" (UFFS, 2020a, online). Um aspecto positivo pertinente à área de processos da instituição é que ela conta com um Manual de Gestão de Processos que "apresenta a metodologia de diagnóstico, modelagem e aperfeiçoamento dos fluxos e processos operacionais da Instituição" (UFFS, 2016, p. 4).

A importância da área de gestão de processos aplicada na estrutura organizacional de universidades, como no caso da UFFS, é corroborada por Paiva et al. (2017) ao destacar que a modelagem do processo de trabalho ajuda a uniformizar os procedimentos e compreensões laborativas por meio da integralização, do estudo e do aprimoramento do encadeamento das informações, as quais são dispostas, posteriormente, em meios documentais.

Quanto ao processo de AS, foi identificado que, em 2017, o EP já fez o mapeamento, a análise, a modelagem dos processos, subprocessos e as rotinas de trabalho a ele associadas, conforme pontuado na literatura (HARRINGTON, 1993; REIS; BLATTMANN, 2004; FALCÃO JÚNIOR; SANTOS, 2016). As regras para a realização da AS e habilitação para inscrição nos auxílios socioeconômicos constam na Resolução $n^{\circ}$ 10/CONSUNI-CGAE/ UFFS/2016. Nos anos seguintes à aprovação dessa resolução, seu texto passou por alterações, visando a adequar o processo às necessidades da $\mathrm{AE}$ e à capacidade de atendimento dos profissionais que conduzem esse processo no SAE. Essas alterações foram incorporadas no desenho do processo, conforme previsto no Manual de Gestão de Processos.

Com o avanço das ações e programas de AE, a UFFS construiu sua política institucional de AE, instituída pela Resolução $n^{\circ}$ 10/ CONSUNI-CGAE/UFFS/2019. Nessa resolução, são definidos os serviços, os programas, os projetos e as ações de $\mathrm{AE}$ da universidade (UFFS, 2019c). O processo de AS passou a constar também no artigo $5^{\circ}$ da Política de AE da UFFS, como uma das etapas requeridas para a comprovação da situação de vulnerabilidade socioeconômica dos estudantes que pretendem acessar as políticas de permanência e AE da universidade.

Conforme o artigo $7^{\circ}$ da Política de AE, a execução desse processo é disciplinada por resolução própria e consta entre as responsabilidades das equipes do SAE de cada campus, sob a gestão/assessoria da PROAE e a supervisão/ fiscalização da Comissão de Acompanhamento e Avaliação dos Programas de Assistência Estudantil (CAAPAE). O artigo $5^{\circ}$ da política de AE ainda ressalta, em seu $\S 1^{\circ}$, que "a situação de vulnerabilidade socioeconômica do estudante será representada pelo Índice de Vulnerabilidade Social (IVS)" e, no $\S 2^{\circ}$, que "primará pela celeridade, pela transparência do processo e, também, pelo rigor da análise realizada, 
combatendo possíveis fraudes" (UFFS, 2019c, online).

A descrição das responsabilidades do serviço de análises socioeconômicas, presente no artigo 11 da política de AE, destaca, entre suas atribuições, "organizar e executar o trabalho de análises socioeconômicas, a partir dos critérios de elegibilidade existentes para concessão de benefícios e acompanhamento aos estudantes, por meio de entrevistas, visitas domiciliares, análise documental, estudos sociais e pareceres técnicos" (UFFS, 2019c, online).

Ainda, o art. 12 da política de AE prescreve que

a análise socioeconômica possui como objetivo analisar a situação socioeconômica dos estudantes, gerando um Índice de Vulnerabilidade Socioeconômica (IVS), mantendo um banco de dados dos estudantes para serem atendidos em programas, projetos, benefícios e serviços que dependam desta análise, conforme regulação em Resolução e Editais específicos (UFFS, 2019c, online).

A metodologia e a fórmula utilizadas no cálculo do IVS constam na Resolução no $10 /$ CONSUNI-CGAE/UFFS/2016, considerando requisitos como a renda familiar bruta mensal, o gasto com moradia do estudante (despesas do aluguel/prestação de financiamento), gasto com moradia dos pais (despesas do aluguel/ prestação do financiamento), gasto com saúde e pessoa com deficiência, gasto com transporte, bens patrimoniais, condições favoráveis e agravantes.

$\mathrm{O}$ processo de AS foi registrado no Manual de Gestão de Processos da UFFS sob o código "MP0023 - Análise Socioeconômica". O fluxo desse processo pode ser observado de forma resumida na figura 1 , adaptada do processo MP0023.
Figura 1 - Processo de Análise Socioeconômica dos estudantes de graduação da UFFS

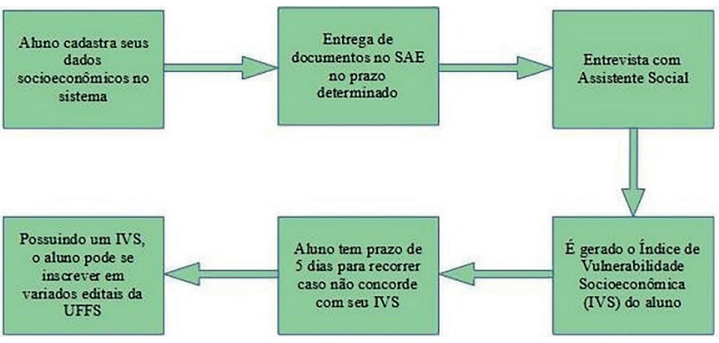

Fonte: elaborada pelos autores.

Em termos práticos, esse processo pode ser descrito da seguinte maneira: inicialmente, o estudante se inscreve para fazer a AS, que é um dos pré-requisitos para ele poder acessar os auxílios financeiros da universidade. Após cadastrar os dados necessários no sistema, o aluno deve levar os documentos originais, em um prazo pré-determinado, para conferência da equipe técnico-administrativa do $\mathrm{SAE}$ e, na sequência, passar por entrevista com um profissional de Serviço Social. Após a entrevista, é gerado o IVS, que servirá de parâmetro para habilitação ao recebimento de um ou mais auxílios para os quais o estudante poderá se inscrever na UFFS, respeitando os valores estabelecidos em edital para cada faixa de IVS e o limite de corte adotado para a concessão de cada auxílio. Ao se inscrever nos editais, o estudante poderá acumular vários auxílios e/ou bolsas, observadas as regras de cada edital e o resultado do cálculo do seu IVS.

Sob a ótica da Gestão de Processos, todas essas etapas estão dispostas em uma modelagem em que o fluxo das operações está dividido em 29 atividades, expostos por meio de símbolos, os quais são estruturados entre dois atores: aluno (demandante do serviço) e servidores técnico-administrativos do SAE. Ainda, dentro dessa mesma modelagem, há também atividades de trabalho que foram registradas em subprocessos, a saber: Renovação Cadastral MP0155, Atualização Cadastral - MP0025 e MP0037 - Auxílios Socioeconômicos (UFFS, 2020b).

Tanto no referido macroprocesso, quanto em seus subprocessos, a maior parte das opera- 
ções são feitas de forma digital, por meio de sistema, excetuando as etapas e atividades que, obrigatoriamente, exigem o manuseio de vias físicas de documentos e/ou a realização de entrevista junto ao Assistente Social. Vale destacar que o processo MP0023 é um subprocesso de outro ainda maior: o MP - 0022 Macroprocesso Assistência Estudantil, o qual abarca também processos de concessão de outras bolsas e demais formas de amparo aos estudantes (UFFS, 2020b).

Após a descrição do processo de AS, foram verificados os apontamentos evidenciados em relatórios de controles publicados no site da universidade que denotam, entre outros, possíveis dificuldades e/ou pontos fracos na execução do processo de AS. Foi observado que, a partir de 2018, a UFFS, por meio da Instrução Normativa $n^{\circ} 2 / P R O A E / U F F S / 2018$, estabeleceu procedimentos para a realização de auditorias no processo de AS. Tal processo visa, sobretudo, reexaminar e monitorar os documentos e as informações utilizadas para gerar o IVS dos alunos, além de permitir um aperfeiçoamento do processo de AS pelos profissionais de serviço social, prevendo, também, uma capacitação permanente para esses servidores. Em síntese, nesse procedimento de auditoria, também denominado de conferência cruzada, um assistente social refaz, majoritariamente, com base documental, o processo de AS já realizado por profissional de serviço social de outro campus e aponta as possíveis inconsciências observadas por meio dessa regulamentação, em dezembro de 2019, foram publicados os resultados da primeira auditoria nesse processo de trabalho. Para a elaboração do IVS com base na documentação entregue pelos estudantes, são considerados, entre outros fatores, a renda familiar, os bens patrimoniais, o número de pessoas do grupo familiar, as despesas com moradia (água, luz, aluguel etc), as despesas com transporte pertinentes à sua atividade acadêmica, as doenças/deficiências crônicas no grupo familiar (UFFS, 2019a). Tal relatório aponta as divergências encontradas entre os dados utilizados na elaboração inicial do IVS e na sua reanálise, deslindados a seguir.
Sobre a renda familiar, observou-se que, em alguns casos, para o seu cálculo, a aplicação dos descontos pode não ter sido seguida corretamente, o que consta na Resolução $n^{\circ} 10 /$ CONSUNI-CGAE/UFFS/2016, a qual estabelece o regramento e a documentação necessários para a AS. Situação similar foi identificada sobre os bens patrimoniais, na qual os profissionais de serviço social relatam que há pouco detalhamento dos bens cadastrados no sistema pelos estudantes, além de afirmarem que "será verificado se tal sinalização não passou de um simples equívoco no preenchimento do cadastro, ou, se de fato, a família possui bens patrimoniais que não foram considerados no processo de análise" (UFFS, 2019a, p. 8). Neste sentido, denota-se que pode haver uma imprecisão, em certas situações, do que pode ou não ser considerado como um bem patrimonial, algo passível de uma capacitação das equipes junto a profissionais de ciências sociais aplicadas, em especial, com formação em contabilidade. Outro aspecto acerca da análise de renda e de bens patrimoniais diz respeito aos núcleos familiares oriundos da agricultura e microempresários, em que o cálculo dos rendimentos se dá de forma diferenciada, de acordo com o tipo de atividade exercida.

A respeito dos comprovantes relativos às despesas com moradia, doença Crônica na família e despesas com transportes, a maioria dos casos relatados versa sobre uma diferença entre o valor cadastrado no sistema e o valor que, de fato, está comprovado nas vias físicas da documentação original. Tais situações apontam que a modelagem do processo MP0023 - análise socioeconômica, descrita anteriormente, pode ser revista de forma a criar-se mais atividades no desenrolar deste fluxo; em especial, entre as atividades 7 e 9, não bastando apenas conferir se o estudante entregou o referido documento, mas, sim, se os dados nele presentes foram cadastrados corretamente.

Em contrapartida, nas questões relativas à parte do grupo familiar, é apontado que não houve nenhuma diferença durante esse processo de auditoria. Segundo o Relatório de Su- 
pervisão de Análises Socioeconômicas 2019, "isso se deve porque nas entrevistas sociais a composição do grupo familiar é bastante explorada pelos assistentes sociais na intenção de identificar exatamente qual é o grupo familiar do estudante" (UFFS, 2019a, p. 6). Este é um aspecto positivo, tendo em vista o conceitual formativo dos profissionais envolvidos atualmente no processo de AS. Seria importante que fossem incorporados, de forma permanente, outros profissionais que pudessem enriquecer tal processo.

$\mathrm{Na}$ configuração do SAE encontrada no momento da pesquisa, observou-se que alguns campi não contam com o rol de profissionais elencados na política de AE. De acordo com essa política, o SAE deve contar com servidores de diversos níveis formativos, entre os quais Assistente Social, Psicólogo, Pedagogo, Técnico em Assuntos Educacionais e Assistente em Administração. Há, ainda, a possibilidade de contratação de estagiários e monitores bolsistas para atuar em projetos e programas previstos na Política de AE da UFFS (UFFS, 2019c).

No entanto, o SAE do Campus Passo Fundo, por exemplo, conta, unicamente, com uma Assistente Social e nenhum outro profissional para auxiliá-la no desempenho das atividades de AE. O SAE do Campus Erechim não dispõe de Técnico em Assuntos Educacionais, e o SAE do Campus Chapecó dispõe de dois Assistentes Sociais, mas não possui Técnico em Assuntos Educacionais nem Assistente em Administração. Isso dificulta a distribuição do trabalho para o desenvolvimento das atividades e o controle sobre os atos administrativos realizados, aumentando o risco de ocorrerem falhas durante o processo.

O relatório também versa que a maioria dos documentos obrigatórios exigidos foi encontrada nos cadastros auditados. Todavia, algumas situações pontuais foram relatadas, entre as quais, a falta de carimbos que atestavam a veracidade da cópia de documentos, ausência de alguns documentos cadastrados no sistema, entre outros (UFFS, 2019a). Importante salientar que a questão da documentação pode ser modificada a qualquer momento por forças externas à instituição, podendo ser extinguidos, modificados e/ou criados novos documentos ou plataformas digitais que poderiam melhor embasar o trabalho dos profissionais envolvidos no processo de AS.

Considerando o encadeamento de tarefas reverberadas em processos e subprocessos, foram encontradas possibilidades de melhoria das rotinas e fluxos de trabalhos que podem ser alcançadas por meio da integração entre a gestão de processos e a gestão por competências (REIS; BLATTMANN, 2004). A gestão por competências possibilita o desenvolvimento das potencialidades dos servidores, visando superar inseguranças e eventuais resistências em prol de melhorias procedimentais e processuais que beneficiem a todos (FLEURY; FLEURY, 2001, 2004; PIRES et al., 2005; MOREIRA; MUNCK, 2010; BERGUE, 2019).

Em face do exposto, observa-se que a UFFS, por meio de seu plano anual de capacitação, poderá adotar melhorias nesse processo, as quais contribuirão com a qualificação das equipes técnicas, para que o processo de AS apresente resultados, cada vez mais, satisfatórios, e as fragilidades encontradas venham a ser gradativamente superadas.

O Plano de Desenvolvimento de Pessoas (PDP) da UFFS apresenta "diretrizes para o processo de desenvolvimento, qualificação e requalificação dos seus servidores" (UFFS, 2020d, online). Nesse documento, estão previstas as condições para licenças, afastamentos e programas de capacitação em serviço de acordo com as regulamentações internas da UFFS para o desenvolvimento de pessoas, em conformidade com o PNDP (BRASIL, 2019). Também consta, no PDP da UFFS, o levantamento de necessidades de capacitação para o ano de 2020 , no qual foi extraída a seguinte observação: "necessidade de qualificar melhor a análise documental dos MEIS (microempreendedores individuais) para a análise de renda e análise socioeconômica". Essa demanda está prevista como uma política de desenvolvimento presencial e foi apontada no relatório de auditoria da AS entre as fragilidades 
encontradas na conferência cruzada realizada pelos profissionais de serviço social.

Conforme observado nos documentos norteadores do processo de AS, a análise documental, realizada em muitas ocasiões pelos Assistentes Sociais, também exige conhecimentos das áreas de Administração e Ciências Contábeis, que, em alguns casos, podem ser supridos pela assessoria dos Assistentes em Administração, caso eles tenham formação em nível superior alinhada com alguma dessas áreas. No entanto, por ser um cargo de nível médio, não há como presumir que o Assistente em Administração lotado no SAE possa, naturalmente, dar esse suporte. Outro aspecto é que a documentação dos estudantes que integra a AS é de caráter pessoal, exigindo, portanto, acesso restrito e sigilo das informações.

Além disso, contatou-se que, apesar de o PDP prever a possibilidade de afastamento para capacitação, na atual configuração do SAE e na formatação que a modelagem do processo se apresenta, torna-se difícil ao profissional de serviço social usufruir desse afastamento, pois, como há apenas um servidor com essa formação no campus, as atividades precisam ser assumidas por profissional de outro campus, localizado a uma distância geográfica significativa, ou supridos pela adoção do atendimento remoto, o que pode comprometer o trabalho de realização das entrevistas, em virtude de o profissional não ter a liberdade necessária para explorar nuances importantes da análise, a exemplo das condições favoráveis e agravantes mencionados na Resolução $n^{\circ} 10$ /CONSUNI-CGAE/UFFS/2016.

Sendo assim, observou-se que o fluxo que envolve o processo de AS é passível de uma nova revisão. Recentemente, a Resolução $n^{0} 5 /$ CONSUNI-CGAE/UFFS/2019 alterou a Resolução $n^{\circ}$ 10/CONSUNI-CGAE/UFFS/2016, descrevendo, em seu art. $2^{\circ}, \S 3^{\circ}$, que a análise de renda realizada pela universidade durante o processo de matrícula de um estudante será usada para compor a AS (UFFS, 2019b).

Ainda, seria interessante avaliar a criação de uma Comissão Permanente de Análise de Renda (COPAR) composta, sobretudo, por profissionais de Contabilidade e/ou Técnico em Contabilidade, a qual pudesse tanto realizar a análise de renda dos alunos ingressantes durante o período de matrícula, quanto também auxiliar o processo de atualização e/ou renovação da AS. Dessa forma, a renda do estudante ingressante por Ação Afirmativa já seria auferida por essa comissão, ficando sob a responsabilidade dos assistentes sociais apenas a entrevista e, a cargo dos assistentes em administração do SAE, a conferência documental e o suporte administrativo/operacional. Vale lembrar que hoje, em muitos dos casos, o uso do cálculo de renda do processo de matrícula não pode ser utilizado de forma integral na AS, servindo apenas para embasar algumas das informações dispostas no art. $11^{\circ}$ da Resolução que rege o processo de AS (UFFS, 2016).

Mesmo com a possibilidade de essas alterações ocorrerem em um futuro próximo, a elevação gradativa do número de matrículas nos cursos de graduação da UFFS e consequente aumento da demanda pela AS, exige que as equipes sejam completadas com os profissionais que ainda faltam para atender ao previsto na política de $\mathrm{AE}$, os quais, ao serem capacitados para tanto, poderão auxiliar o processo de conferência documental, de modo que as atividades não exclusivas do serviço social possam ser desenvolvidas pelo Assistente em Administração do SAE, o que, na conjuntura atual, não está sendo viabilizada, gerando, além da sobrecarga de trabalho para os Assistentes Sociais, a possibilidade de ocorrerem falhas no processo, por falta de conhecimento técnico na área de Administração e/ou Ciências Contábeis.

Para viabilizar a reestruturação do processo de AS, é indispensável contar com um perfil profissional proativo para o cargo de Assistente em Administração do SAE e que ele possua o rol de conhecimentos necessários para uma análise documental qualificada, nos moldes previstos na Resolução 10/CONSUNI-CGAE/UFFS/2016 (UFFS, 2016). Diante disso, percebe-se a necessidade de estratégias de capacitação e desenvolvimento de competências profissionais nas áreas 
de conferência documental, com foco específico para a análise de renda e avaliação de bens patrimoniais. Essa trilha de capacitação precisa ser direcionada, inicialmente, aos assistentes em administração lotados no SAE e aos assistentes sociais, pois, na conjuntura atual, alguns campi não possuem outros profissionais além do assistente social para a realização da $\mathrm{AS}$, o que não permite a revisão do processo em curto prazo. Ademais, quando essa demanda por profissionais puder ser suprida, será necessário que todos os membros das equipes sejam treinados para o exercício de suas funções e possam desempenhar suas atribuições relacionadas ao processo de AS satisfatoriamente.

\section{CONCLUSÃO}

O objetivo central deste artigo é propor estratégias de capacitações das equipes técnicas responsáveis pelo processo de análise socioeconômica (AS) dos estudantes de graduação. Ao analisar o fluxo desse processo, desenvolvido na UFFS, constatou-se que o processo está sendo operacionalizado, majoritariamente, pelos assistentes sociais do SAE e que esses profissionais não detêm todo o conhecimento necessário para a operacionalização do processo. Além disso, os profissionais da área de serviço social concentram atividades que poderiam ser direcionadas para a área administrativa ou contar com o apoio de uma comissão com profissionais especializados em análise de renda e avaliação patrimonial.

Vislumbrou-se a possibilidade de revisão do processo, de melhoria da estrutura de pessoal no âmbito do SAE e de qualificar esses novos profissionais para uma ação efetiva. No que se refere à qualificação, observou-se que a trilha de capacitação proposta precisa ser ofertada como programa de capacitação em serviço, dadas as peculiaridades de carência de profissionais observadas e as dificuldades que a ausência desses profissionais por longos períodos pode acarretar o atendimento aos estudantes. Esse processo de treinamento e desenvolvimento de competências precisa ser estendido aos profissionais que já estão atuando no SAE e também aos novos profissionais. Portanto, trata-se de um programa de educação continuada que precisa ser inserido no PDP da instituição. Destaca-se, também, a necessidade de avançar na realização de estudos sobre dimensionamento de pessoal, para viabilizar novas possibilidades de capacitação profissional aos servidores e melhorar continuamente o atendimento aos estudantes.

Outro fator importante na análise é que os profissionais do SAE podem participar da composição da comissão de análise de renda, estabelecida durante o período de realização das matrículas. Mesmo que, em muitos casos, o processo de análise de renda feito na matrícula do aluno possa não estar atualizado no momento da solicitação de AS, é importante que a metodologia seja unificada para que ,quando for possível utilizar esse cálculo na AS, ele seja efetivamente aproveitado. Isso reduzirá etapas no processo de avaliação cadastral desses estudantes, conferindo maior agilidade e evitando possíveis retrabalhos. Ao haver o entrelaçamento entre a análise de renda da matrícula e a AS, a oferta de cursos de educação continuada sobre temas como a análise de renda e avaliação patrimonial da AS deverá ser disponibilizada para todos os profissionais envolvidos no processo de análise de renda, independentemente de atuarem no SAE. Essa troca de conhecimento e experiências permitirá um alinhamento maior entre esses profissionais e suas demandas de trabalho.

Atrelado ao desempenho, também podem-se considerar aspectos como a elevação da qualidade de vida no trabalho dos servidores, pois os fluxos procedimentais do processo de AS exigem a observância de uma série de etapas pré-estabelecidas, as quais são atribuídas a profissionais com formação específica para a sua realização, mas que, ao ingressarem na universidade, ainda não têm o domínio desse tipo de atividade. Portanto, o desenvolvimento de competências está, intimamente, ligado a ações de capacitação e educação continuada que, por conseguinte, impactam os processos sistêmicos laborais desses trabalhadores. 


\section{REFERÊNCIAS}

AVONA, M.; BIGI, E. A; BIGI, G. C. N. Gestão de Competências: os impactos sobre as organizações e as pessoas. Revista de Administração do Unisal, v. 4, n. 6, dez. 2014. Disponível em: http://www.revista.unisal.br/sj/ index.php/RevAdministracao/article/view/376. Acesso em: 23 jul. 2021.

BERGUE, Sandro Trescastro. Gestão de pessoas: liderança e competências para o setor público. Coleção Gestão pública. Brasília: ENAP, 2019. Disponível em: https://repositorio.enap. gov.br/bitstream/1/4283/1/7_Livro_Gest\%C3\%A3o\%20de\%20pessoas\%20lideran\%C3\%A7a\%20e\%20compet $\%$ C3\%Aancias $\% 20$ para $\% 20 \mathrm{o} \% 20$ setor $\% 20 \mathrm{p} \% \mathrm{C} 3 \%$ Bablico.pdf. Acesso em: 23 jul. 2021.

BRASIL. Decreto $n^{0}$ 5.707, de 23 de fevereiro de 2006. Institui a Política e as Diretrizes para o Desenvolvimento de Pessoal da administração pública federal direta, autárquica e fundacional, e regulamenta dispositivos da Lei no 8.112, de 11 de dezembro de 1990. Brasília, DF: Presidência da República, 2006. Disponível em: http://www.planalto.gov.br/ccivil_03/ ato2004-2006/2006/decreto/d5707.htm. Acesso em: 10 out. 2020.

BRASIL. Decreto no 9.094 de 17 de julho de 2017. Dispõe sobre a simplificação do atendimento prestado aos usuários dos serviços públicos, ratifica a dispensa do reconhecimento de firma e da autenticação em documentos produzidos no País e institui a Carta de Serviços ao Usuário. Brasília, DF: Presidência da República, 2017. Disponível em: http://www.planalto. gov.br/ccivil_03/_ato2015-2018/2017/decreto/ d9094.htm. Acesso em: 10 out. 2020.

BRASIL. Decreto $n^{0} 9.991$ de 28 de agosto de 2019. Dispõe sobre a Política Nacional de Desenvolvimento de Pessoas da administração pública federal direta, autárquica e fundacional, e regulamenta dispositivos da Lei $\mathrm{n}^{\mathrm{o}} 8.112$, de 11 de dezembro de 1990, quanto a licenças e afastamentos para ações de desenvolvimento.
Brasília, DF: Presidência da República, 2019. Disponível em: http:/www.planalto.gov.br/ccivil_03/_Ato2019-2022/2019/Decreto/D9991. htm\#art35. Acesso em: 5 out. 2020.

BRASIL. Ministério do Planejamento, Orçamento e Gestão. Guia de Gestão de Processos do Governo. 2011. Disponível em: http:// www.gespublica.gov.br/content/guia-de-ges$\mathrm{t} \% \mathrm{C} 3 \%$ A3o-de-processos. Acesso em: 7 out. 2020 .

BRASIL. Ministério Público Federal. Procuradoria Geral da República. Secretaria Jurídica e de Documentação. Escritório de Processos. Manual de gestão por processos. Brasília: MPF/PGR, 2013. Disponível em: https://rfp. sesc.com.br/moodle/pluginfile.php $/ 4611 / \mathrm{mod}$ resource/content $/ 1 /$ Gestao $\% 20$ por $\% 20$ processos.pdf. Acesso em: 8 out. 2020.

CARVALHO, K. A.; SOUSA, J. C. Gestão por processos: novo modelo de gestão para as instituições públicas de ensino superior. Revista Administração em Diálogo, v. 19, n. 2, p. 1-18, 2017.

DAVENPORT, T. H. Reengenharia de processos: como inovar na empresa através da Tecnologia da Informação. 2. ed. Rio de Janeiro: Campus, 1994.

FALCÃO JÚNIOR, M. A. G.; SANTOS, R. N. M. A gestão de processos na análise das atividades de seleções públicas simplificadas: estudo de caso em uma prefeitura. NAVUS - Revista de Gestão e Tecnologia, Florianópolis, v. 6, n. 2, 2016. Disponível em: http://navus. sc.senac.br/index.php/navus/article/view/324. Acesso em: 27 set. 2020.

FLEURY, M. T. C. L.; FLEURY, A. C. Construindo o conceito de competência. RAC - Revista de Administração Contemporânea, v. 5, 2001, p. 183-196, 2001. Disponível em: https:// www.redalyc.org/articulo.oa? $\mathrm{id}=84009310$. Acesso em: 22 jul. 2020. 
FLEURY, M. T. C. L.; FLEURY, A. C. Alinhando estratégia e competências. RAE - Revista de Administração de Empresas, v. 44, n. 1, p. 44-57, 2004. Disponível em: https://www.scielo.br/pdf/rae/v44n1/v44n1a12.pdf . Acesso em: 22 jul. 2020.

GONÇALVES, J. E. L. As empresas são grandes coleções de processos. Revista de Administração de Empresas (RAE), São Paulo, v. 40, n. 1, p. 6-19, jan./mar. 2000. Disponível em: https://www.scielo.br/scielo.php?script=sci_arttext\&pid=S0034-75902000000100002. Acesso em: 1 out. 2020.

HARRINGTON, H. J. Aperfeiçoando Processos Empresariais. São Paulo: Makron Books, 1993.

MARCONI, M. de A.; LAKATOS, E. M. Fundamentos de metodologia científica. 4. ed. São Paulo: Atlas, 2002.

MOREIRA, W. R.; MUNCK, L. O processo de alinhamento entre estratégias e competências organizacionais. Revista Alcance, v. 17, n. 2, p. 77-90, 2010. Disponível em: https://www.redalyc.org/articulo.oa?id=477748590007 Acesso em: 7 out. 2020 .

OLIVEIRA, D. P. R. Sistemas, organização e métodos: uma abordagem gerencial. 15. ed. São Paulo: Atlas, 2005.

PAIVA, K. C. M.; LOPES, M. C. O. Competências, Gestão de Competências e profissões: perspectivas de pesquisas. RAC - Revista de Administração Contemporânea, v. 12, n. 2, p. 339-368, abr./jun. 2008. Disponível em: https:// www.redalyc.org/articulo.oa? $\mathrm{id}=84012204$. Acesso em: 23 jul. 2021.

PAIVA, M. B. M. et al. Barreiras e facilitadores na gestão de processos de trabalho em Instituição Federal de Ensino Superior. Revista GUAL, Florianópolis, v. 10, n. 4, p. 47-71, Edição Especial 2017.
PIRES, Alexandre Kalil et al. Gestão por competências em organizações de governo. Brasília: ENAP, 2005. Disponível em: http:/www. enap.gov.br/documents/52930/585077/livro gestao_competencias.pdf/cd493b19-485e-42b1-bc0e-27578a89faea. Acesso em: 23 jul. 2021.

PRODANOV, C. C.; FREITAS, E. C. Metodologia do trabalho científico: métodos e técnicas da pesquisa e do trabalho acadêmico. 2. ed. Novo Hamburgo: Feevale, 2013.

REIS, M. M. O.; BLATTMANN, U. Gestão de Processos em Bibliotecas. Rev. Digital de Biblioteconomia e Ciência da Informação, Campinas, v. 1, n. 2, p. 1-17, jan./jun. 2004. Disponível em: https://periodicos.sbu.unicamp.br/ojs/index.php/rdbci/article/view/2077. Acesso em: 3 out. 2020.

TRIVIÑOS, Augusto Nibaldo Silva. Introdução à pesquisa em ciências sociais: a pesquisa qualitativa em educação. São Paulo: Atlas, 1987.

UNIVERSIDADE FEDERAL DA FRONTEIRA SUL - UFFS. Instrução Normativa $\mathbf{n}^{0}$ 2/ PROAE/UFFS/2018. Dispõe sobre os procedimentos normativos para a realização de auditorias nos processos de análise socioeconômica. Disponível em: https://www.uffs.edu. br/atos-normativos/instrucao-normativa/proae/2018-0002. Acesso em: 24 out. 2020.

UNIVERSIDADE FEDERAL DA FRONTEIRA SUL - UFFS. Manual de Gestão De Processos. [2020a]. Disponível em: https://www. uffs.edu.br/institucional/a_uffs/processos/ manuais/manual-de-gestao-de-processos/@@ download/file. Acesso em: 20 out. 2020.

UNIVERSIDADE FEDERAL DA FRONTEIRA SUL - UFFS. Macro Processo 0023. [2020b]. Disponível em: https://www.uffs.edu. br/pastas-ocultas/bd/proplan-dplan/processos/ processos-academicos-discente/mp0023. Acesso em: 21 out. 2020. 
UNIVERSIDADE FEDERAL DA FRONTEIRA SUL - UFFS. Setor de Assuntos Estudantis nos campi. [2020c]. Disponível em: https:// www.uffs.edu.br/institucional/pro-reitorias/assuntos-estudantis/servico-de-atendimento-ao-estudante. Acesso em: 7 out. 2020.

UNIVERSIDADE FEDERAL DA FRONTEIRA SUL - UFFS. Plano de Desenvolvimento de Pessoas - PDP 2020. [2020d]. Disponível em: https://www.uffs.edu.br/institucional/pro-reitorias/gestao-de-pessoas/capacitacao-dos-servidores/cursos. Acesso em: 19 out. 2020.

UNIVERSIDADE FEDERAL DA FRONTEIRA SUL - UFFS. Relatório de supervisão de Análise Socioeconômicas - 2019. [2019a]. Disponível em: https://www.uffs.edu.br/institucional/pro-reitorias/assuntos-estudantis/repositorio-pro-reitoria-de-assuntos-estudantis/ relatorio-de-supervisao-de-analises-socioeconomicas-2018. Acesso em: 23 out. 2020.

UNIVERSIDADE FEDERAL DA FRONTEIRA SUL - UFFS. Resolução n⿳ 10/CONSUNI-CGAE/UFFS/2016. Estabelece regras para a realização de análise socioeconômica e habilitação para inscrição nos auxílios socioeconômicos. 2016. Disponível em: https://www. uffs.edu.br/atos-normativos/resolucao/consunicgae/2016-0010\#: :text=Estabelece $\% 20$ regras $\% 20$ para $\% 20 \mathrm{a} \% 20$ realiza $\% \mathrm{C} 3 \% \mathrm{~A} 7 \%$ C $3 \%$ A 3 o,para $\% 20$ ins cri $\%$ C $3 \%$ A $7 \%$ C3\%A3o\%20nos\%20aux\%C3\%ADlios\%20 socioecon $\% \mathrm{C} 3 \% \mathrm{~B} 4 \mathrm{micos}$. Acesso em: 24 out. 2020.

UNIVERSIDADE FEDERAL DA FRONTEIRA SUL - UFFS. Resolução no 5/CONSUNI-CGAE/UFFS/2019. Altera a Resolução n ${ }^{0}$ 10/ CONSUNI-CGAE/2016, que estabelece regras para a realização de análise socioeconômica e habilitação para inscrição nos auxílios socioeconômicos. [2019b]. Disponível em: https:// www.uffs.edu.br/atos-normativos/resolucao/ consunicgae/2019-0005. Acesso em: 9 nov. 2020 .
UNIVERSIDADE FEDERAL DA FRONTEIRA SUL - UFFS. Resolução n ${ }^{0}$ 10/CONSUNI-CGAE/UFFS/2019. Institui a Política de Assistência Estudantil no âmbito da Universidade Federal da Fronteira Sul. [2019c]. Disponível em: https://www.uffs.edu.br/atos-normativos/ resolucao/consunicgae/2019-0010. Acesso em: 15 out. 2020 .

YIN, Robert K. Estudo de caso: planejamento e métodos. Tradução Daniel Grassi. 2. ed. Porto Alegre: Bookman, 2001. 